\title{
Cardiac transplantation in the United Kingdom
}

Sir,

The report from the Council of the British Cardiac Society (1984; 52: 679-82) quotes the Stanford experience and gives the one and five year survival figures as $63 \%$ and $39 \%$ respectively. Interestingly, these figures are virtually identical with the survival rates for a group of 169 patients with dilated cardiomyopathy (the principal indication for cardiac transplantation) who were treated medically at the Hammersmith Hospital. The one year and five year mortality rates of that group were reported to the British Cardiac Society as $34.7 \%$ and $59.4 \%$ respectively. ${ }^{1}$

Council's suggestion that cardiac transplantation prolongs life is, on this evidence, difficult to accept, particularly in view of the fact that on an "intention to treat" basis the surgical survival figures would be con- siderably worse-that is, because of the high early mortality in the sizeable group of clearly very sick patients who did not survive long enough to receive a transplant.

David Wainwright Evans,

Regional Cardiac Unit,

Papworth Hospital,

Cambridge CB3 8RE.

\section{Reference}

1 Diaz R, Obasohan A, Newman H, Goodwin JF, Oakley C. Prognostic indicators in dilated cardiomyopathy [Abstract]. Br Heart $\mathcal{F}$ 1985; 53: 114.

\section{The presentation of symptomatic heart disease in infancy based on 10 years' experience (1973-82)}

Sir,

I was interested to read the paper by Scott et al (1984; 52: 248-57) on the Brompton Hospital's experience of the presentation of symptomatic heart disease in infancy. Although the authors recognise that the prevalence rates are unreliable, they make repeated reference to the New England Infant Program. The New England Infant Program is a comprehensive community study, the figures from which must be closer to the true prevalence than those from one centre in London. Further distortion of the figures quoted by the Brompton Hospital arises from the different case selection by the referring paediatrician, who will avoid sending infants to the Brompton if a major non-cardiorespiratory anomaly that may need active concurrent treatment is present.

I would also like to mention that repeated reference is made to the value of joint paediatric cardiology clinics and would like to endorse this statement. I learnt the value of these clinics from the late Dr Ronald Mackeith in 1969 and introduced them to the Brompton Hospital from 1965 onwards.

Michael Joseph, Department of Paediatric Cardiology, Brompton Hospital, London SW3 6HP, and Guy's Hospital, London SE1 9RT.

\section{Notices}

\section{European Society of Cardiology}

A meeting of the European Society of Cardiology (working group on valvular prosthesis) will be held on 11 and 12 October 1985. The subject of this meeting will be "Quantification of valvular regurgitations: appraisal of new techniques." Inquiries about this meeting should be addressed to Professor R Kremer, Cliniques Universitaires de Mont-Godinne, B-5180 Yvoir, Belgium.

\section{British Cardiac Society}

The Annual General Meeting for 1985 will take place in Birmingham on 17 and 18 April 1985, and the closing date for receipt of abstracts was 8 January 1985.

The Autumn Meeting will be held at the Wembley Conference Centre, London, on 26 to 28 November 1985 , and the closing date for receipt of abstracts will be 1 August 1985 . 